\title{
Grid Tie Photovoltaic Inverter for Residential Application
}

\author{
Tan Kheng Kwang (Corresponding author) \\ School of Electrical and Electronic Engineering \\ University Sains Malaysia, Engineering Campus \\ 14300 Nibong Tebal, Seberang Perai Selatan, Pulau Pinang, Malaysia \\ E-mail: edwardrtan_tchtch@yahoo.com \\ Syafrudin Bin Masri \\ School of Electrical and Electronic Engineering \\ University Sains Malaysia, Engineering Campus \\ 14300 Nibong Tebal, Seberang Perai Selatan, Pulau Pinang, Malaysia \\ E-mail: syaf_ee@yahoo.com
}

Received: April 11, 2011

Accepted: April 25, 2011

doi:10.5539/mas.v5n4p200

\begin{abstract}
This paper presents a grid tie inverter (GTI) in photovoltaic, PV system for residential application. The focus of this paper is on the switch mode DC-AC inverter. The proposed GTI will be switched with a combination switching strategy of square wave and the sinusoidal pulse width modulation, SPWM. The combination switching strategy will be discussed and the performance of the inverter also will be simulated under grid tie condition in SIMULINK. Moreover, the strategy of sending power into the grid also will be discussed.
\end{abstract}

Keywords: Photovoltaic, Inverter, Grid Tie, Sine-wave Pulse Width Modulation, Square Wave

\section{Introduction}

With the increase of human population of the world and the rapid growth of the global economic, the demand of the energy resources especially electricity faced a tremendous increase. According to the U.S. Energy Information Administration in the International Energy Outlook 2009 said that the global electricity generation is predicated to be increase from 18 trillion $\mathrm{kWh}$ in 2006 to 23.2 trillion $\mathrm{kWh}$ in 2015 and will further increase to 31.8 trillion $\mathrm{kWh}$ for the next 5 years. With such rapid increase in electricity demand, using conventional and classical electricity generation by burning the fossil fuel to fulfill the electricity demand is no longer able fulfill the demand. Besides that, burning the fossil fuel will result in environmental problems. The emission of carbon dioxide, methane and other greenhouse gasses will result in global warming problem. Moreover, after ratify of the Kyoto and Copenhagen accord by most of the countries in the world, this conventional method is now no longer a legal way to generate electricity.

This has given an opportunity for the renewable energy resources and technology to take over the electricity generation process. One of the renewable and believe to be unlimited energy resources is from the Great Sun or commonly known as the solar energy. Photovoltaic, PV is a technology first observed and developed back in 1839 by Alexandre-Edmond Becquerel that will convert the solar energy to electricity. Since then, the PV technology had come across with tremendous change and development, starting from few watt stand alone system to few mega watt grid connected system.

The conventional PV system is as shown in figure 1. The PV array or module will produce an inconstant DC voltage. This inconstant DC voltage will then pass though a constant output voltage with maximum power point tracker, MPPT DC-to-DC converter. For grid tie and conventional application, after having this constant DC voltage, an inverter will be employed to convert it to line frequency AC voltage.

\section{Idea of design}

A conventional inverter can be divided into two parts, one is the power circuit part and the other is the control circuit part. The power circuit is normally built up from MOSFET or IGBT switches. The simplest power circuit of the inverter is built up from four switches with two parallel to each other as shown in Figure 2.(Rashid, M. H. 1995)(Mohan, N., Undeland, T., and Robbins, W., 1995)(Issa Batarseh, 1995)

These four switches are switching in a predesigned sequence by sending a signal to the gate pin of the switches. This signal is generated by the control circuit. This control circuit is normally built from analog op-amp circuit or digital micro-controller or even combination of both analog and digital. In the inverter design, the control signal is design to be pulse width modulation, PWM in most of the time. However, in some inverter design where the output voltage waveform shape is very importance, the sinusoidal pulse width modulation, SPWM as 
shown in Figure 3 is used to reduce the harmonic contain in the output waveform and provide better quality of the output voltage.

In switching process, the four switches are grouped into two groups, $G_{1}$ and $G_{2}$ is in one group and $G_{3}$ and $G_{4}$ is in another. When $G_{1}$ and $G_{2}$ are switched and $G_{3}$ and $G_{4}$ is forced to be off by the signal from the control circuit, the output voltage from the inverter will be in positive, however, if $G_{3}$ and $G_{4}$ are switched and $G_{1}$ and $G_{2}$ is forced to be off, the inverter will give a negative voltage as the output. (Rashid, M. H. 1995)(Mohan, N., Undeland, T., and Robbins, W., 1995)

For a grid tie inverter or GTI, its design is slightly different from the stand alone inverter or inverter using in variable speed controller. The output voltage of a GTI should obey some requirements so that the inverter can be connected to the grid and sending power into the grid. The rules or requirements that to be obeyed are: (V. Meksarik, S. Masri, S. Taib, and C. M. Hadzer, 2007)(Soeren Baekhoej Kjaer, John K. Pedersen, Frede Blaabjerg., 2005)(Sachin Jain, and Vivek Agarwal, 2007)

1) The voltage magnitude and phase must be equal to the grid.

2) The frequency of the output voltage from the inverter must be exactly equal to the grid frequency. $(50 \mathrm{~Hz}$ for Malaysia).

To make sure that the output of the GTI obeys the above rules, the grid voltage is sampled and as a reference for the design of the switching signal.

Besides, the load of the GTI also different from the stand alone or the variable speed controller inverter. The GTI have a load of the power grid where the load contains power much more high compare to the GTI. This require for the GTI to force the power generated from the PV into the grid. The real and reactive power flow of the GTI into the grid is shown in Equation 1 and 2. (V. Meksarik, S. Masri, S. Taib, and C. M. Hadzer, 2003)

$$
\begin{aligned}
& \text { Real Power, } Q=\frac{\left|V_{\text {inv }}\right|\left|V_{\text {grid }}\right|}{Z_{t}} \sin \sigma \\
& \text { Reactive Power, } Q=\frac{\left|V_{\text {inv }}\right|^{2}}{Z_{t}}-\frac{\left|V_{\text {inv }}\right|\left|V_{\text {grid }}\right|}{Z_{t}} \cos \sigma \\
& \text { Where, } \quad V_{i n v} \quad=\text { Inverter Output Voltage } \\
& V_{\text {grid }} \quad=\text { Power grid voltage } \\
& Z_{t} \quad=\text { Impedance of the linking line } \\
& \text { a } \quad=\text { Angle different between } \mathrm{V}_{\text {inv }} \text { and } \mathrm{V}_{\text {grid }}
\end{aligned}
$$

From Equation 1, it is very clear that in order to send the maximum real power into the grid, the phase angle $u$ should be at 90 degree. However, for the stability limit of the GTI, this angle must not be 90 degree and should be lower than that. However, for Equation 1, the value of $\sin \varepsilon$ can have both positive and negative value. For positive value, output voltage of the inverter leading the grid voltage, the real power will flow from the GTI to the grid but if the value is negative then the real power will flow from the opposite direction.

\section{Proposed design}

\subsection{Proposed circuit}

The proposed power circuit of the inverter in this paper is as shown in Figure 2 above. This is a very simple inverter design consist of four numbers of IGBT gates, two parallel with each other. For the control circuit, the proposed design will be consisted of combination of analogue and digital circuit. The analogue circuit will be used to generate the signal require to do the switching of the power circuit and the digital circuit which is consist of the micro-controller that will be act as the brain of the control circuit. The digital circuit will control the generate signals so that the signal will be in sequence.

\subsection{Proposed switching technique}

In a conventional inverter design, normally the switching will used only one type of the switching technique only. However, in this proposed design instate of using one type of switching signal to switch the inverter, a combination of SPWM and square wave is used. With this kind of combination switching, the switching loss across the switches of the inverter will be greatly reduced due to reduce of switching frequency. The block diagram of the proposed switching circuit is as shown in Figure 4.

In order to simplify the synchronizing process, instate of generating the sine wave from the analog oscillator or from the microcontroller and digital-to-analog converter (DAC), the sine wave of the proposed design will be sampled from the power grid by using the voltage transformer to step down the $230 \mathrm{~V}$ grid voltage to $5 \mathrm{~V}$. With the sine wave sampled from the grid and used to generate the SPWM signal, the frequency of the output voltage from the GTI will be having the same frequency as the grid voltage where this is one of the most important requirement for the GTI as stated in the introduction. After having the sine wave sampled from the grid, this sampled sine wave is rectified by a precision rectifier as shown in Figure 4. The precision rectifier will rectify the sine wave from the grid to waveform as shown in Figure 5. 
Besides processing the sampled sine wave, to produce a SPWM signal, a high frequency triangle wave also required. In this proposed design the high frequency triangle wave wills also generated by the analog oscillator and the frequency will be $10 \mathrm{kHz}$ as shown in Figure 6.

These two signals will then pass though a comparator to produce SPWM for the switching signal. These two signals will produce a uni-polar SPWM as shown in Figure 3. The uni-polar SPWM signal have only positive value and will be change from $+5 \mathrm{~V}$ to $0 \mathrm{~V}$ and back to $+5 \mathrm{~V}$ again.

Besides, having the SPWM signal for the switching of the IGBT as many conventional inverter circuits, the proposed GTI will also have square wave signal for the switching. This square wave signal will be in line frequency $(50 \mathrm{~Hz}$ for Malaysia) and in phase with the SPWM as shown in Figure 7. This square wave signal will pass though a NOT gate and creating another set of signal which is $180^{\circ}$ out phase from the original square wave.

After having the SPWM and square wave signal, since the inverter having 4 numbers of MOSFET switches, the inverter require 4 sets of switching signal to control the gates. To produce 4 sets of signal, the two sets of square wave signal are undergo the AND operation with the SPWM signal and produce 4 set signals as shown in Figure 8 to switch the MOSFET switches. These 4 sets of switching signal can divide into 2 groups. The first group consists of the SIGNAL (A) and SIGNAL (B) from Figure 8. This group will switch the gate $\mathrm{G}_{1}$ and gate $\mathrm{G}_{2}$ and at the same time, the gate $\mathrm{G}_{3}$ and gate $\mathrm{G}_{4}$ will stay off to provide positive output voltage for the inverter on the first half cycle. The second group consists of SIGNAL (C) and SIGNAL (D) from Figure 8. This group will act on the second half on the cycle by switching gate $G_{3}$ and $G_{4}$ and at the same time, gate $G_{1}$ and $G_{2}$ will force to off condition to provide negative voltage at the output of the inverter. The output voltage of the inverter before filtering process is as shown in Figure 9.

Besides having the analog circuit to generate the SPWM and the square wave signal, a digital circuit will used to manage the signal. The signal generated by the analog circuit must be controlled to avoid they operated out of the sequence. To perform this task, a micro-controller is employed. The micro-controller will ensure that the square wave signal that generate by analog must be in phase with the sampled sine wave and the triangle wave must be in correct sequence. The micro-controller operation for the proposed design is shown in Figure 10.

\subsection{Power sending}

As stated in section 2, sending power from the GTI into the power grid needs the voltage angle of the GTI to be leading the grid voltage angle. To able this, a phase shifter circuit is insert into the system. After the sine wave is sampled from the grid, the waveform is passed though the phase shifter to able to make the leading condition.

To sending the maximum power to the grid, theoretically the leading angle, $\sigma$ as shown in equation 1 must be in $90^{\circ}$. However, in practical, due to the stability issue, $\sigma$ will be not be exactly $90^{\circ}$ but low then $90^{\circ}$. Figure 10 shown the output real power versus angle different, $\sigma$.

Besides that, the line impedance, $Z_{t}$ also plays a very importance role in sending power to the power grid. In most of the inverter design, a LC low pass filter will be employed at the output of the inverter to reduce the harmonic influence. This LC filter will increase the $Z_{t}$ and result in reduce of the maximum power sending as shown in equation 1.

\subsection{Design operation}

The operation of the proposed inverter can be divided into two parts. The first part is the synchronizing and the second part is the power sending.

On the synchronizing part, the inverter will generate the output in phase with the grid. This is done by sample the sine wave and set the phase shift to zero. This un-shifted sine wave will be rectified and compare with the high frequency triangle wave to produce the SPWM signal. This SPWM signal will then undergo an AND operation with the square wave and produce 4 set of the signal as shown in figure 8 . The first set of signal in figure 8 will switch gate $G_{1}$ in figure 2 , second set of signal will switch gate $G_{2}$, third set of signal will switch gate $G_{3}$, forth set of signal will switch gate $\mathrm{G}_{4}$.

With this kind of switching, when gate $\mathrm{G}_{2}$ is $\mathrm{ON}$ condition, gate $\mathrm{G}_{1}$ will be switched with SPWM signal and both $\mathrm{G}_{3}$ and $\mathrm{G}_{4}$ will force to the OFF state. This will result in a positive output voltage at the inverter. To produce the negative part of the output voltage, instate of forcing gate $\mathrm{G}_{3}$ and $\mathrm{G}_{4}$ to OFF state, gate $\mathrm{G}_{1}$ and $\mathrm{G}_{2}$ is forced to be OFF and $\mathrm{G}_{4}$ is in ON condition while $\mathrm{G}_{3}$ is switched by the SPWM signal.

With this kind of switching and zero phase shifts, the output voltage of the inverter will be controlled with the same phase with the grid. Having the grid and inverter voltage to be in phase, the zero crossing of both voltages is detected. Once the zero crossing is detected, the contactor between the grid and inverter is activated and tie the grid and inverter together.

After both voltages are tied together, the proposed inverter will have to send power to the grid. On this part, the phase shifter at the control circuit of the proposed inverter will shift the inverter output voltage to be leading the grid voltage with an angle of $a$. With this angle different the inverter will send real and reactive power as shown in equation 1 and 2. 
Besides, to avoid the grid to having power from the inverter when the gird is down and create unnecessary accident, the circuit breaker between the grid and the inverter will break when the grid losing its power and isolate the inverter from the grid. This isolation or islanding process is to avoid the grid to become live part on the time when is should not be. In this process, the circuit breaker is shunt tripped by the relay where this relay will censor the grid with a current transformer $(\mathrm{CT})$. Once the grid loss their power, the relay will active and shunt trip the circuit breaker.

\subsection{Output voltage and harmonic}

One of the most importance parameter of the designed switching strategy that will influence the performance of the inverter is the amplitude modulation, $\mathrm{M}_{\mathrm{A}}$. The amplitude modulation is define as the ratio between the sine waveform which also know as reference signal $\mathrm{V}_{\mathrm{r}}$, and the triangular waveform also know as carrier signal $\mathrm{V}_{\mathrm{c}}$. Mathematically, the $\mathrm{M}_{\mathrm{A}}$ is define as shown in equation 3.

$$
M_{A}=\frac{V_{r}}{V_{c}}
$$

This $\mathrm{M}_{\mathrm{A}}$ play a vary importance role in determine the output voltage of the inverter. Theoretically, as the $\mathrm{M}_{\mathrm{A}}$ value increase, the AC output voltage of the inverter also will increase. A simulation using Matlab Simulink had been done to the proposed switching to predict the output voltage with deferent value of $\mathrm{M}_{\mathrm{A}}$. Figure 12 show the graph $\mathrm{M}_{\mathrm{A}}$ against the RMS output voltage for the input DC voltage at $24 \mathrm{~V}$.

From figure 12, it can conclude that the output RMS voltage will increase as the $\mathrm{M}_{\mathrm{A}}$ increase. However, this increase can be categorized into two parts. The first part is when $\mathrm{M}_{\mathrm{A}}<1$ and the second part is when $\mathrm{M}_{\mathrm{A}}>1$. For $M_{A}<1$, the increase of the RMS voltage as the $M_{A}$ increase is large. This is because as the $M_{A}$ increased, the "ON" duration of the SPWM signal will be longer resulting in the power electronic gates to be in the "ON" state for longer time. Figure 13(a) and 13(b) show the SPWM signal for $\mathrm{M}_{\mathrm{A}}=0.1$ and $\mathrm{M}_{\mathrm{A}}=0.9$ respectively.

For $\mathrm{M}_{\mathrm{A}}>1$, the RMS voltage will still increase as the $\mathrm{M}_{\mathrm{A}}$ increase. However, the rate of the increase will be far lower than when $\mathrm{M}_{\mathrm{A}}$ is less than 1 and this increase will stop at a voltage level equal to the input DC voltage when the $\mathrm{M}_{\mathrm{A}}$ is very large until the SPWM become always in the "ON" level. Figure 14 show the SPWM signal for $\mathrm{M}_{\mathrm{A}}=2$.

Besides will influence the output voltage of the inverter, the $\mathrm{M}_{\mathrm{A}}$ also will influence the output harmonic. As the MA increase from 0 to 1 , the total harmonic distortion (THD) of the output will decrease. However, thing change when the MA value increase after the unity value. This can be clearly found out from the result of the simulation using Matlab Simulink showing in figure 15. In figure 15, the THD values show in the graph is the values that not pass through the LC filter.

So, to get the high voltage level with low harmonic contain so that the filter design is more easy, the $\mathrm{M}_{\mathrm{A}}$ value is choose in between 0.8 to 0.9 . At this $\mathrm{M}_{\mathrm{A}}$ value we can get the output voltage to be in $20-21 \mathrm{~V}$ for the $24 \mathrm{~V}$ DC input and the voltage THD around $38-39 \%$ with any filtering process. After having the filtering process, the voltage THD will further reduce to much lower level.

\section{Simulation result}

The proposed design will undergo a computer simulation using MATLAB Simulink. In this simulation the switching frequency is fixed at $10 \mathrm{kHz}$ and the output on the inverter is step up using a step up transformer with ratio 15:230. Figure $11-14$ shown the output of the inverter and the amount of the power send at the leading angle, $u$ of $45^{\circ}$

From figure 16, it is clearly find out that the current of the proposed inverter require about 2 cycles $(0.04$ second for $50 \mathrm{~Hz}$ system) to become stable after the contactor tie the inverter to the grid. This transition period is result by the sudden adding of power into the power grid. The magnitude and the period of this transition current are very much depending on the impedance of the power grid.

On the transition period, the real and reactive power will fluctuate a lot. The real power will shoot to $75 \mathrm{~W}$ and come to stable at $70 \mathrm{~W}$. For the reactive power, it will over shoot to -32 VAR and stable to -25 VAR. The negative value of the reactive power show that the proposed inverter having a capacitor characteristic. So, the inverter can be also used to improve power factor

\section{Conclusion}

A single phase grid tie inverter with its switching control strategy is presented. A grid tie condition is simulated by using MATLAB. The proposed combination switching strategy perform well in the grid tie condition and able to send a very near sine wave current to the grid.

\section{References}

Bo Yang, Wuhua Li, Yi Zhao, Xiang ning He (2010). Design and Analysis of a grid-connected photovoltaic power system, Power Electronics, IEEE Transactions on Power Electronics, Vol. 25 pg992.

HTTP://WWW.EIA.DOE.GOV/OIAF/IEO/ELECTRICITY.HTML (JAN2010)

Issa Batarseh, (2004). Power Electronic Circuits, John Wiley \& Sons, Inc. 
Mohan, N., Undeland, T., and Robbins, W., (1995). Power Electronic:Converters, Applications, and Designs, 2nd ed., John Wiley \& Sons,New York.

N. Kasa, T. Iida and H. Iwamot, (1999). An inverter using buck-boost type chopper circuits for popular small-scale photovoltaic system, Industrial Electronics Society, 1999, IECON' 99 Proceeding, Vol.1 pg.185-190 Rashid, M. H. (1993). Power Electronics, Circuits, Devices, and Applications, Prentice-Hall, Englewood Cliffs.

S.C. Zheng, X.L. Liu and L.S. Ge, (2007). Study on photovoltaic Generation and Its Islanding Effect, Industrial Electronics and application, 2007, ICIEA 2007. Pg 2328-2332

Sachin Jain, and Vivek Agarwal, (SEPT 2007). A Single stage Grid Connected Inverter Topology for Solar PV System With Maximum Power Point Tracking, IEEE TRĀNSACTIONS ON POWER ELECTRONICS, VOL. 22 No. 5

Soeren Baekhoej Kjaer, John K. Pedersen, Frede Blaabjerg., (SEPT. 2005). A Review of Single-Phase Grid-Connected Inverters for Photovoltaic Modules. IEEE TRANSACTIONS ON INDUSTRY APPLICATION, VOL. 41 , No. 5

V. Meksarik, S. Masri, S. Taib, and C. M. Hadzer (2003). Simulation of Parallel-Loaded Resonant Inverter For Photovoltaic Grid Connected, National Power and Energy Conference (PECon), Malaysia

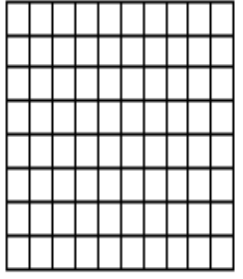

PV Array

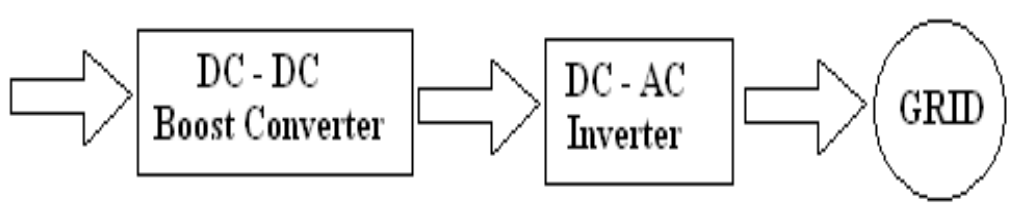

Figure 1. Grid tie PV system topology

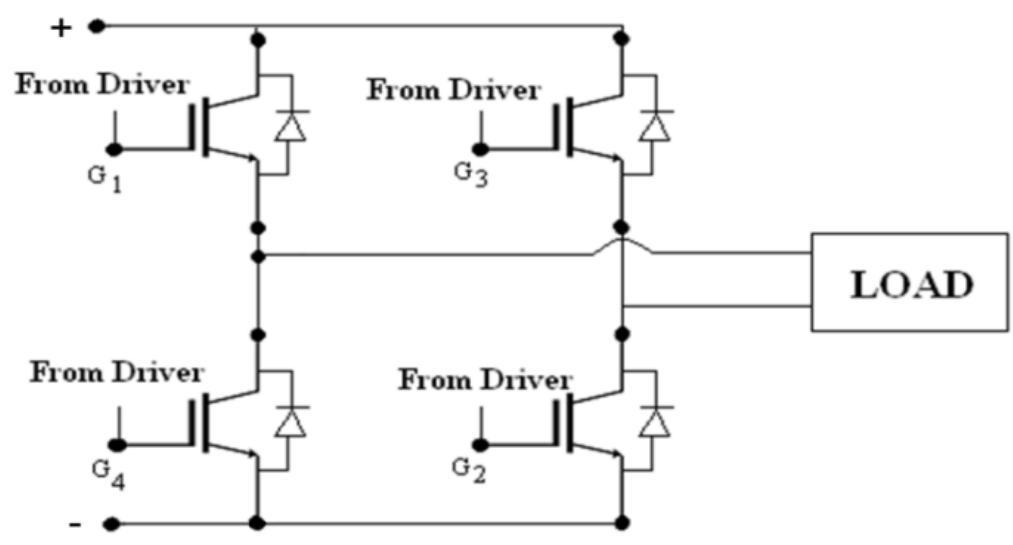

Figure 2. The inverter power circuit 


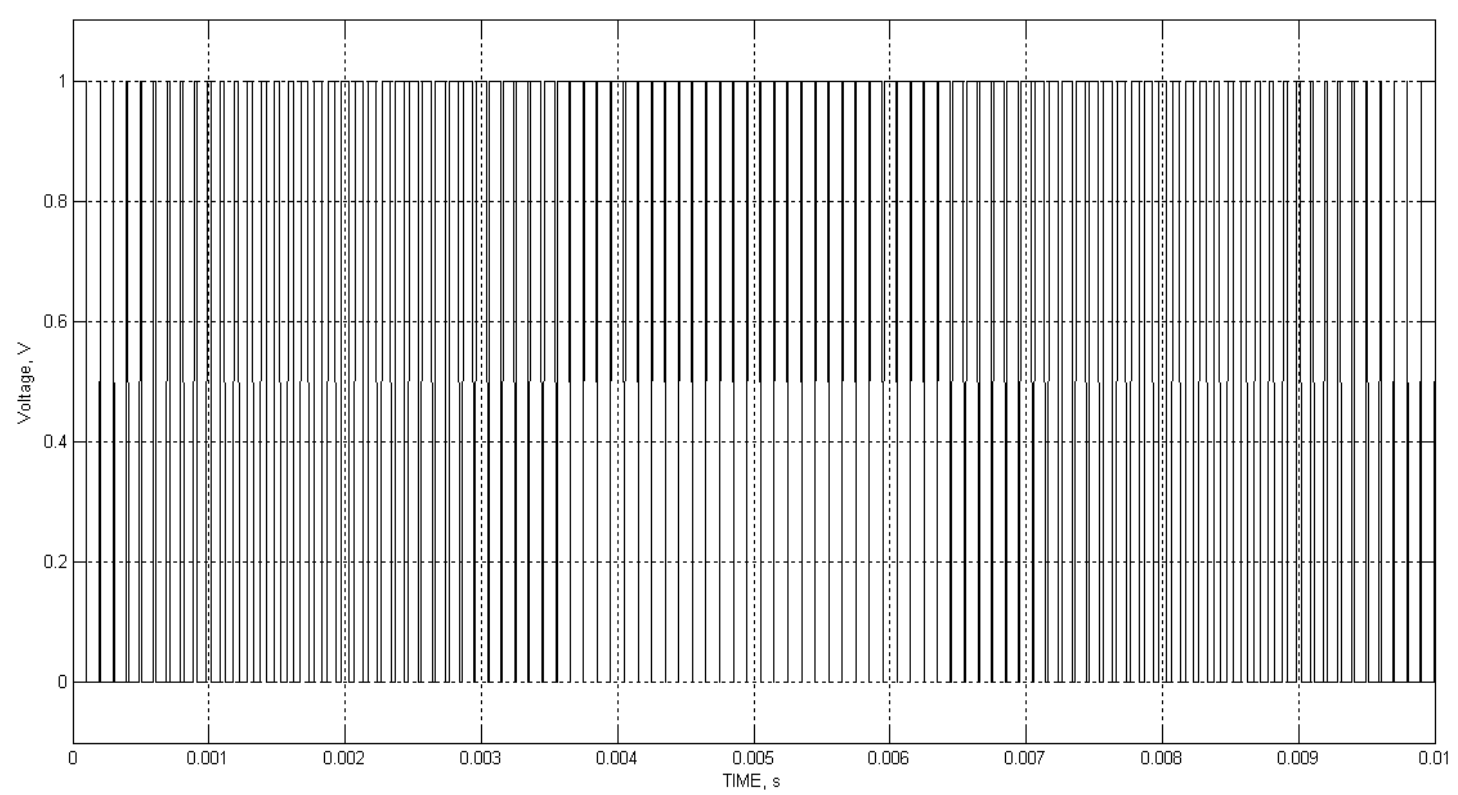

Figure 3. The SPWM signal

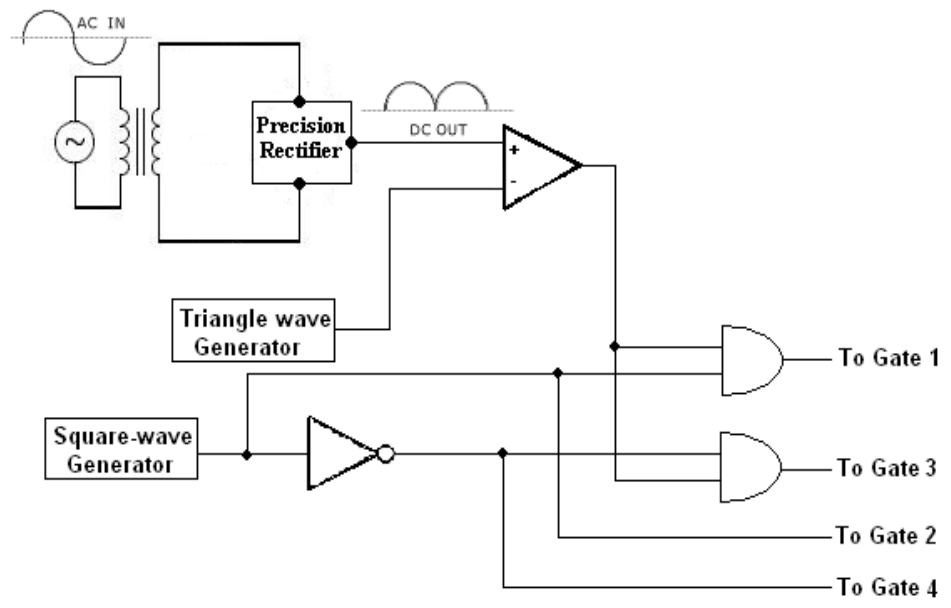

Figure 4. Low power control circuit for proposed design

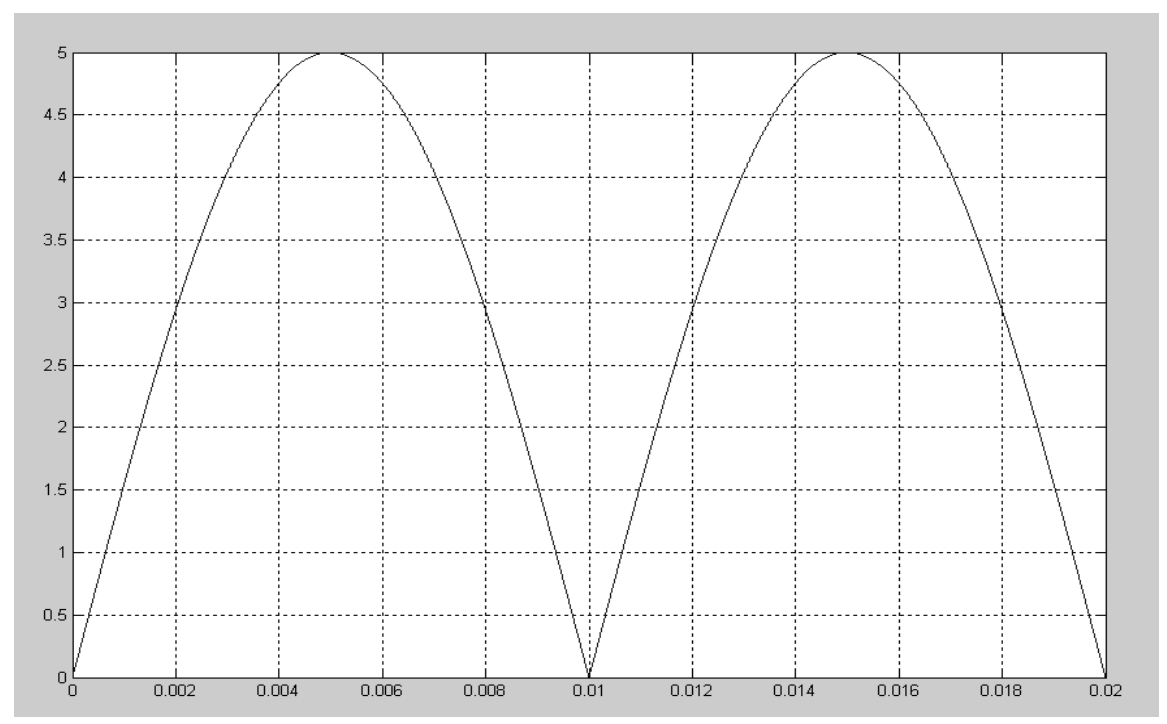

Figure 5. Rectified sine wave 


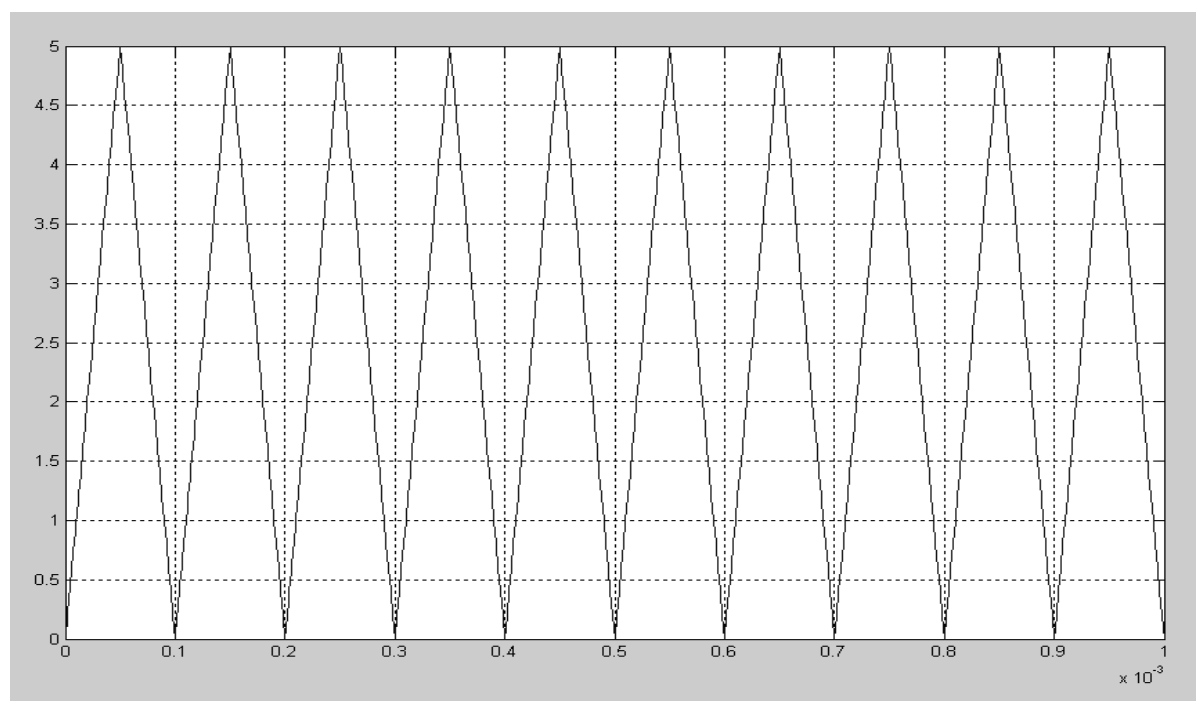

Figure 6. High frequency triangle wave

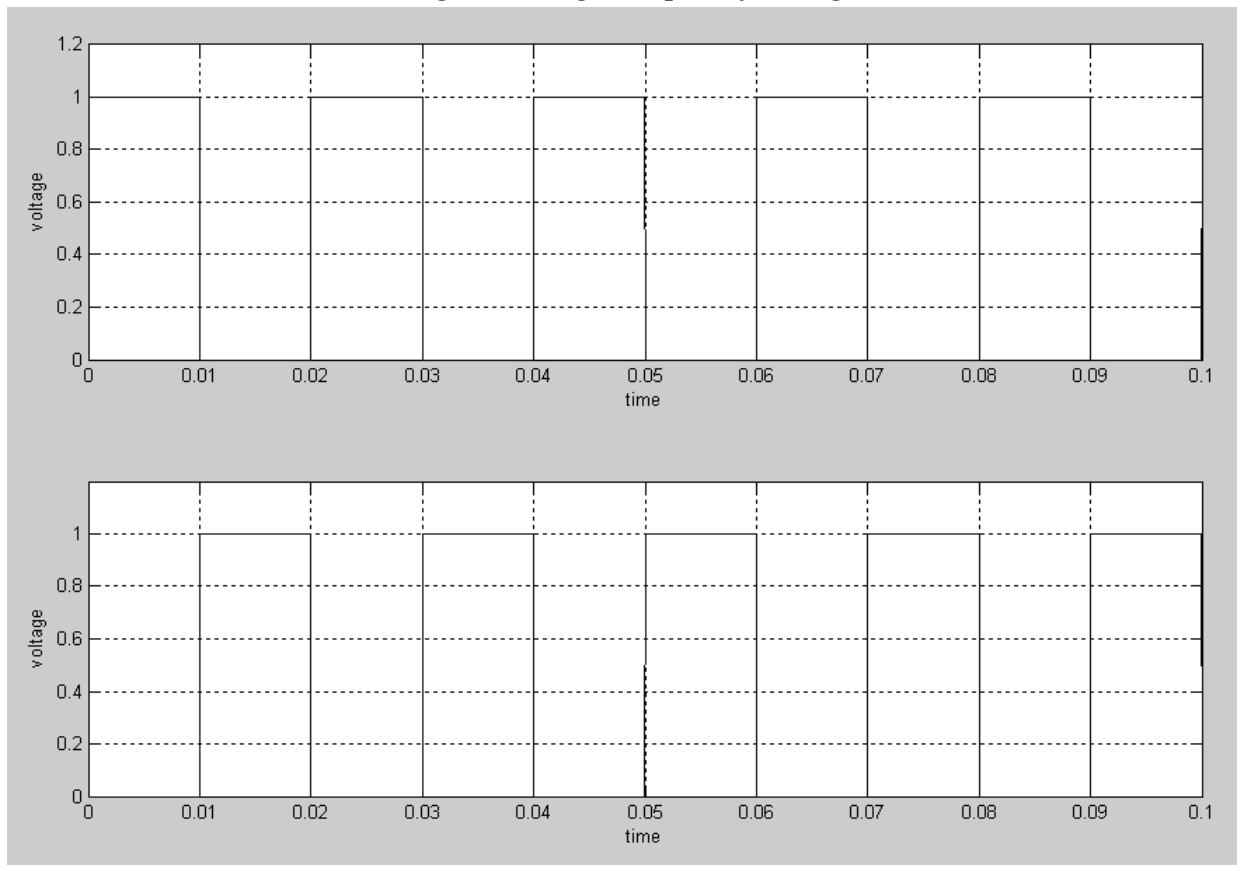

Figure 7. Square wave 

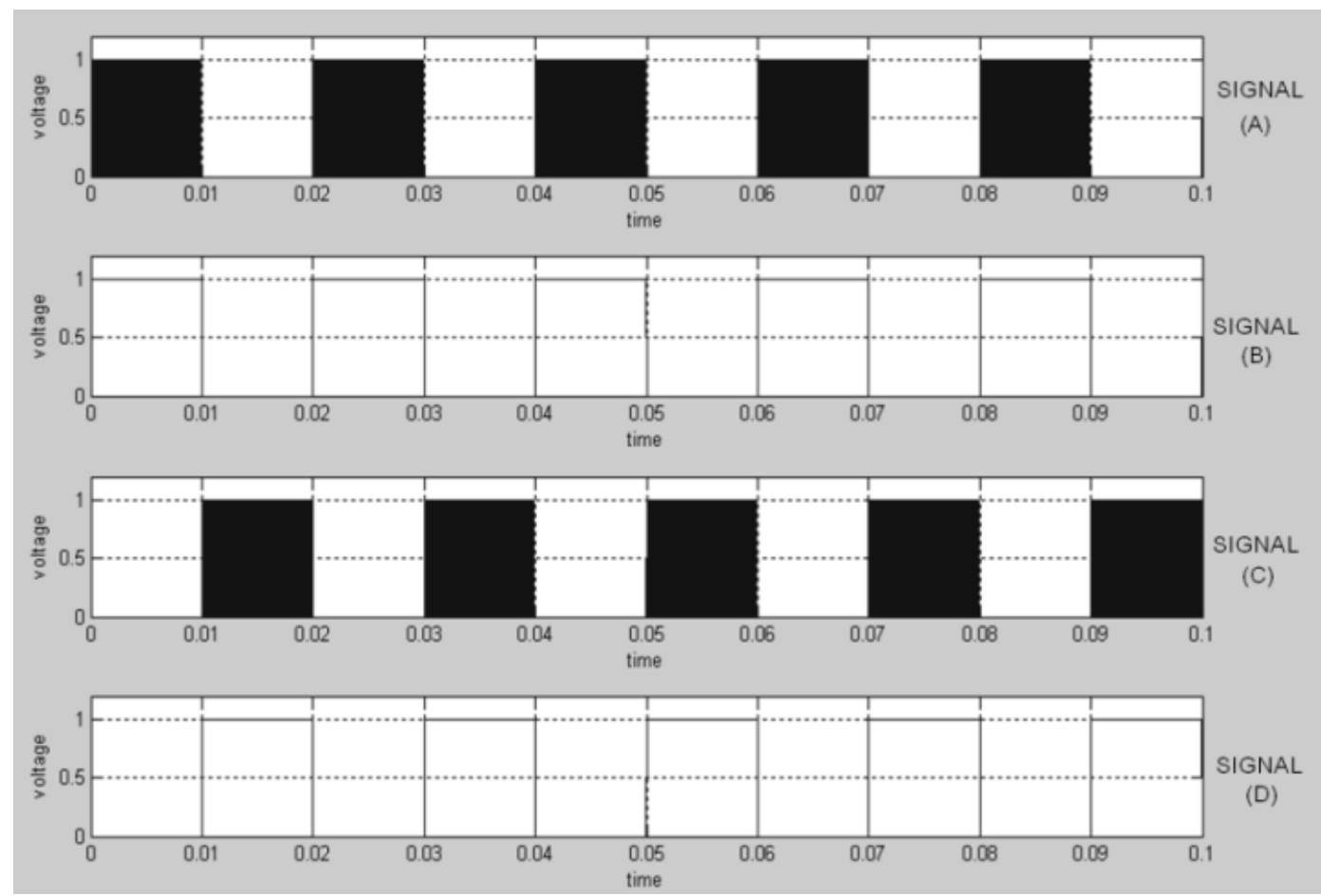

Figure 8. Output of the control circuit

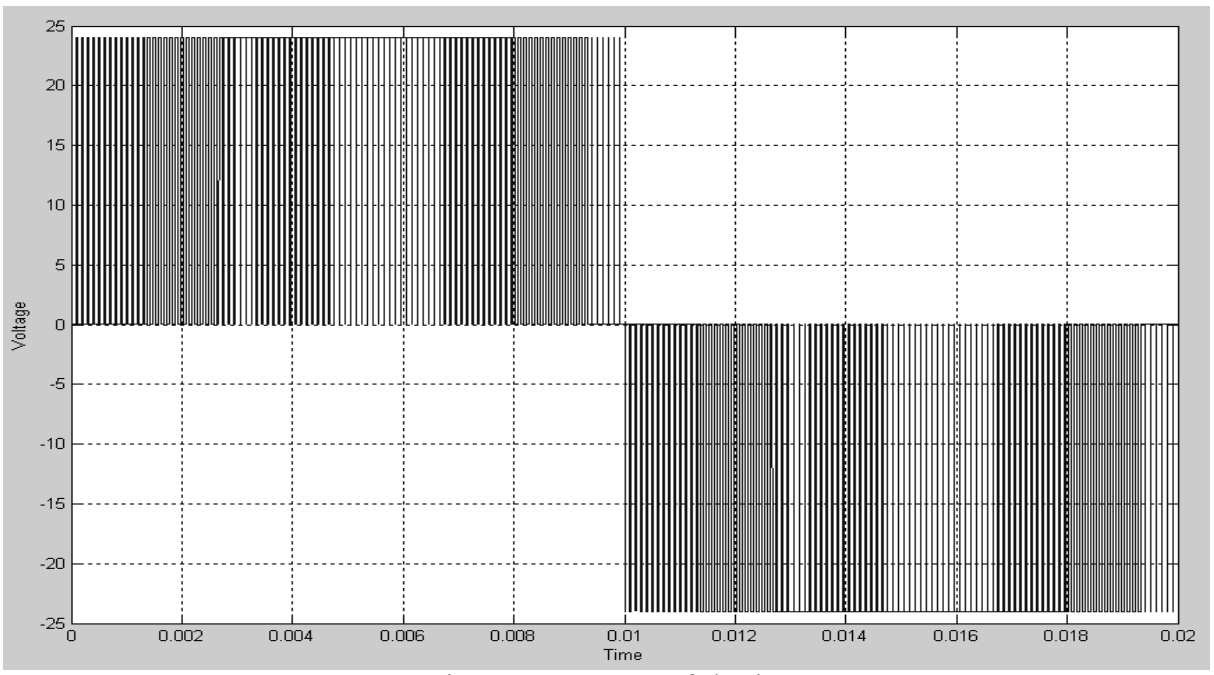

Figure 9. Output of the inverter

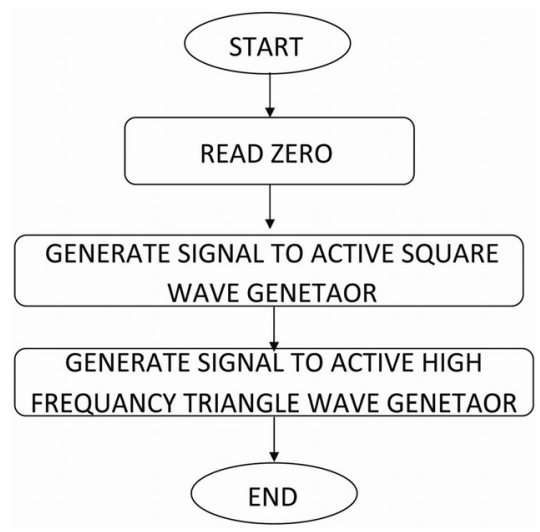

Figure 10. Flow chart of the mirco-controller 


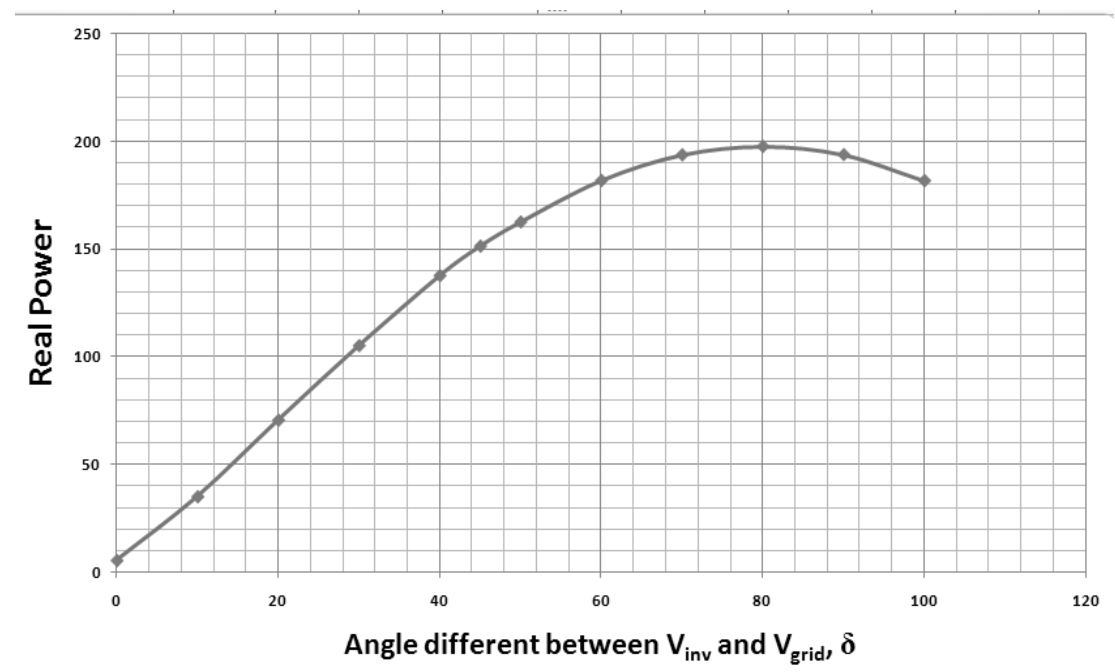

Figure 11. Output real power the inverter again angle different

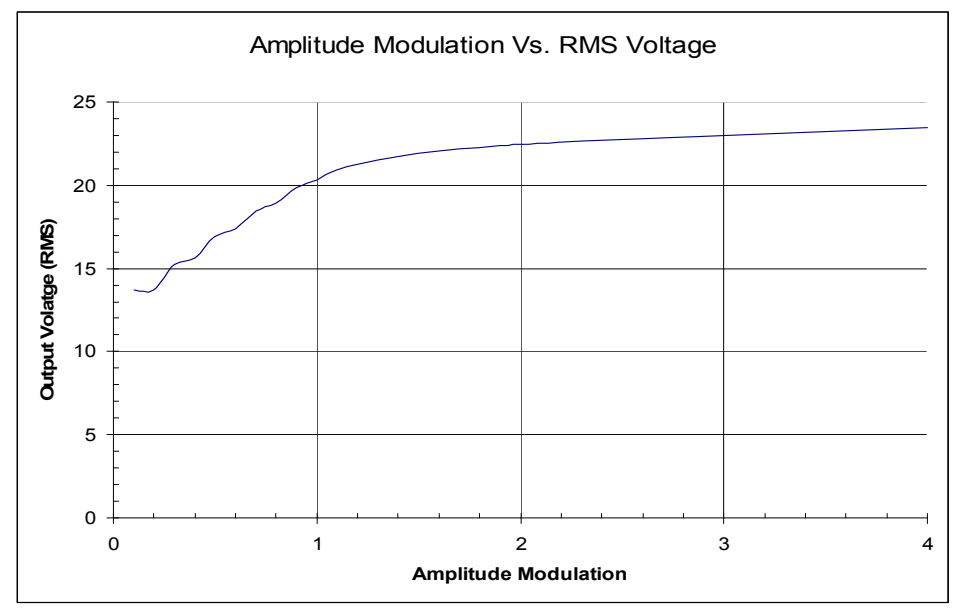

Figure 12. Amplitude Modulation $\mathrm{M}_{\mathrm{A}}$ vs. RMS Voltage

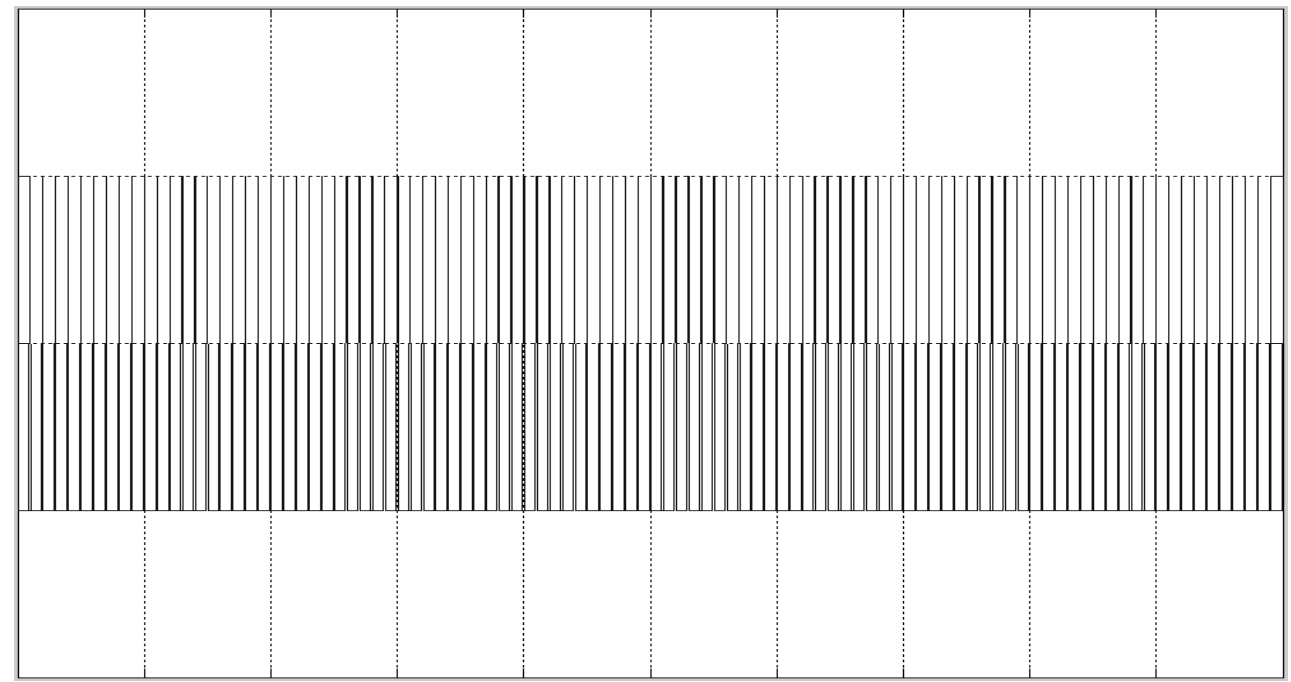

(a) 


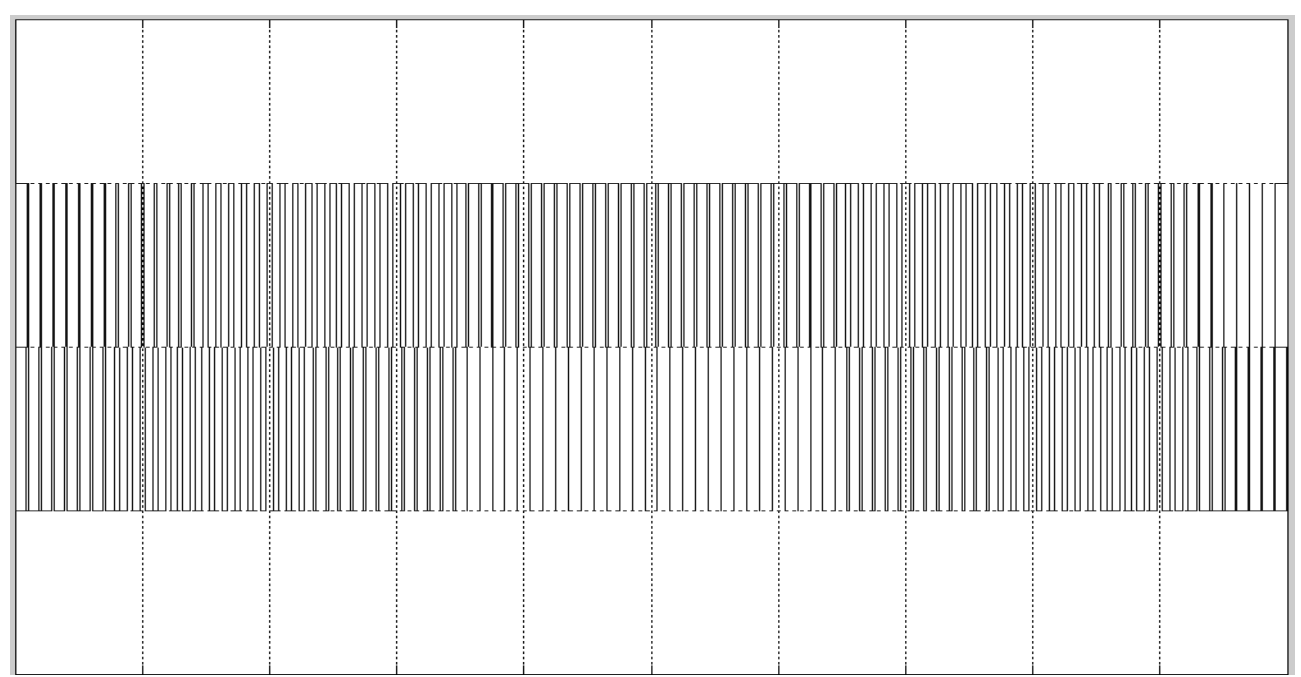

(b)

Figure 13. SPWM signal (a) $\mathrm{M}_{\mathrm{A}}=0.1$

(b) $\mathrm{M}_{\mathrm{A}}=0.9$

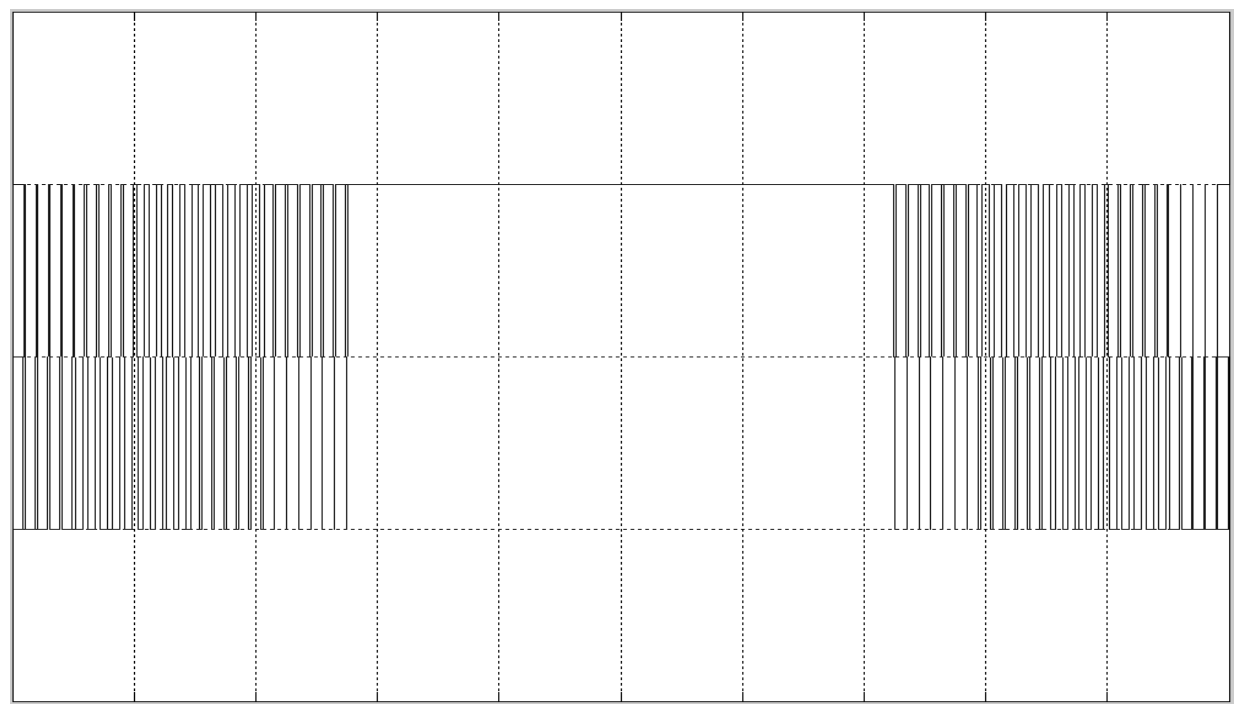

Figure 14. SPWM signal for $\mathrm{M}_{\mathrm{A}}=2$

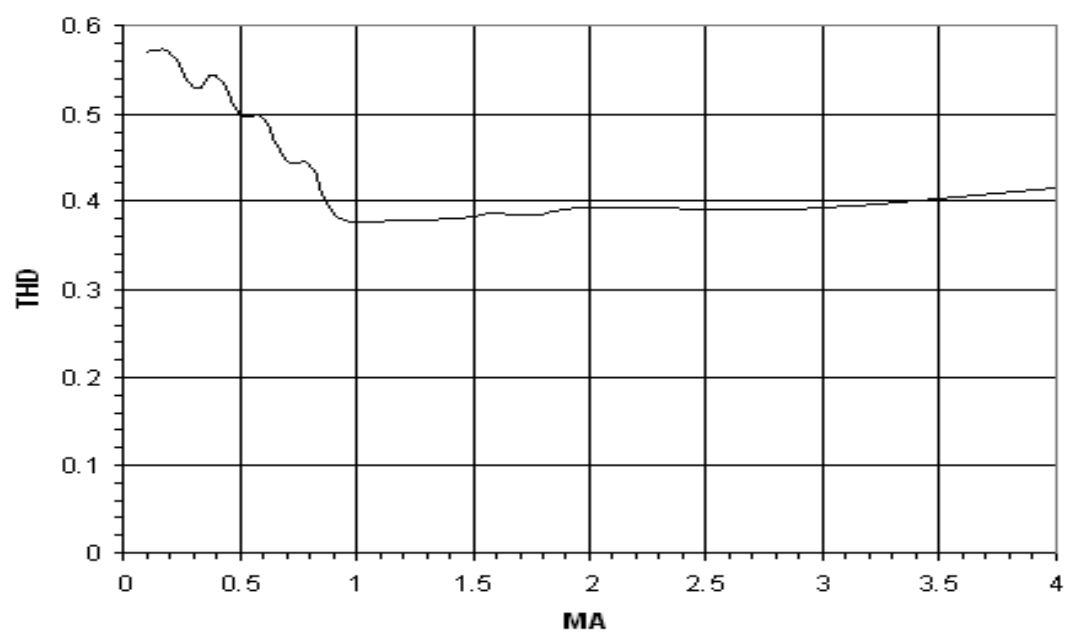

Figure 15. Amplitude Modulation $\mathrm{M}_{\mathrm{A}}$ vs. THD 


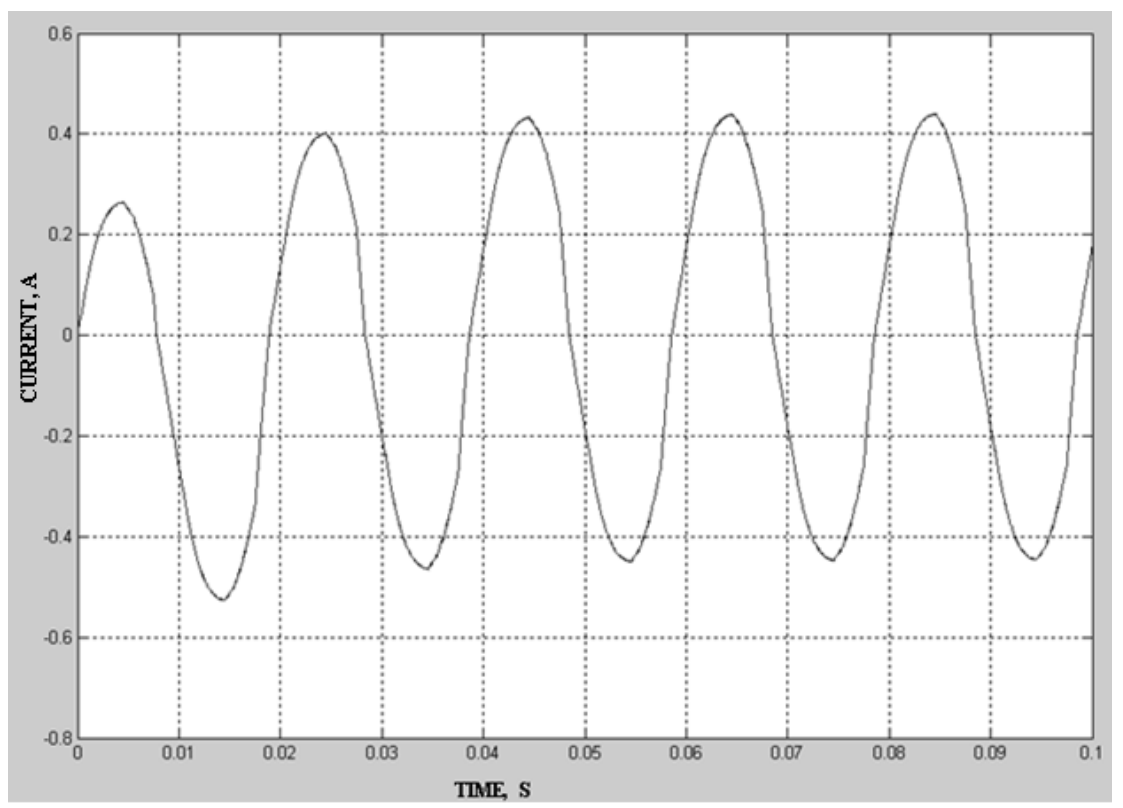

Figure 16. Output Current of the inverter

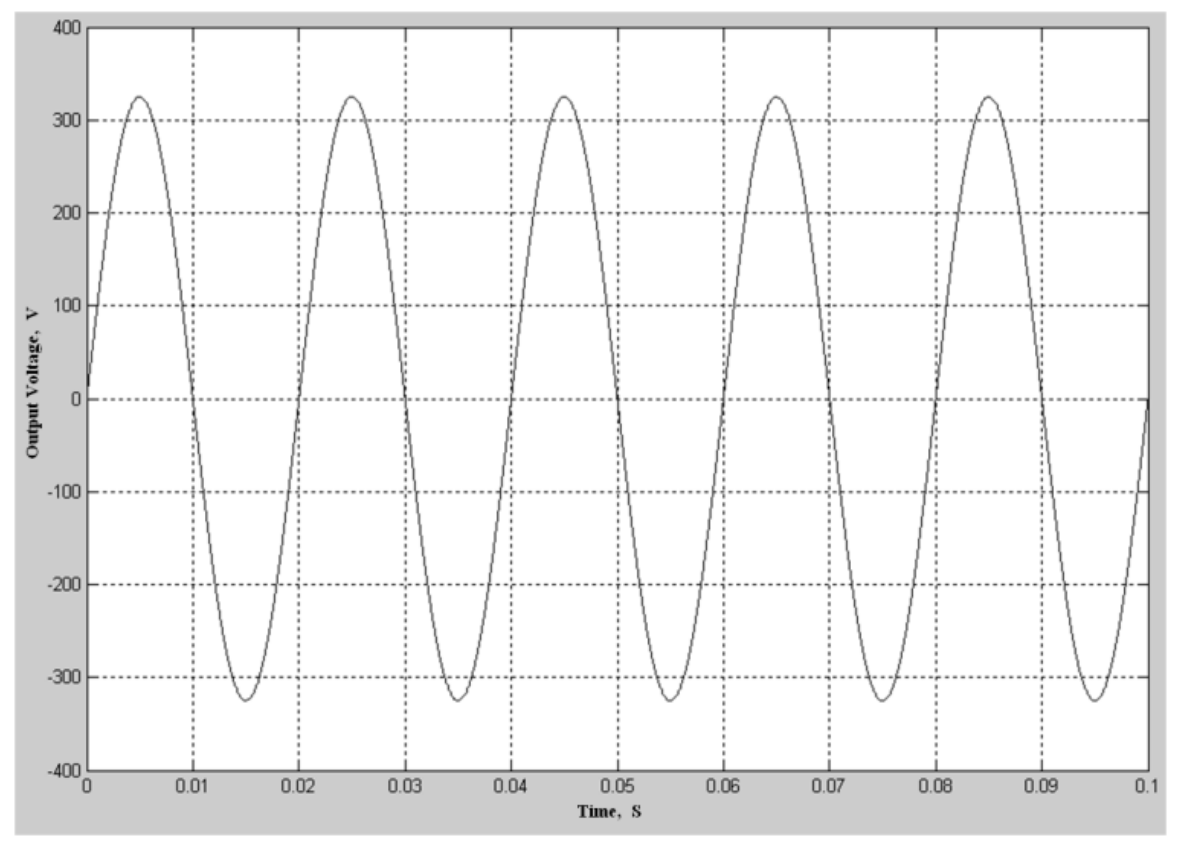

Figure 17. Output Voltage of the inverter 


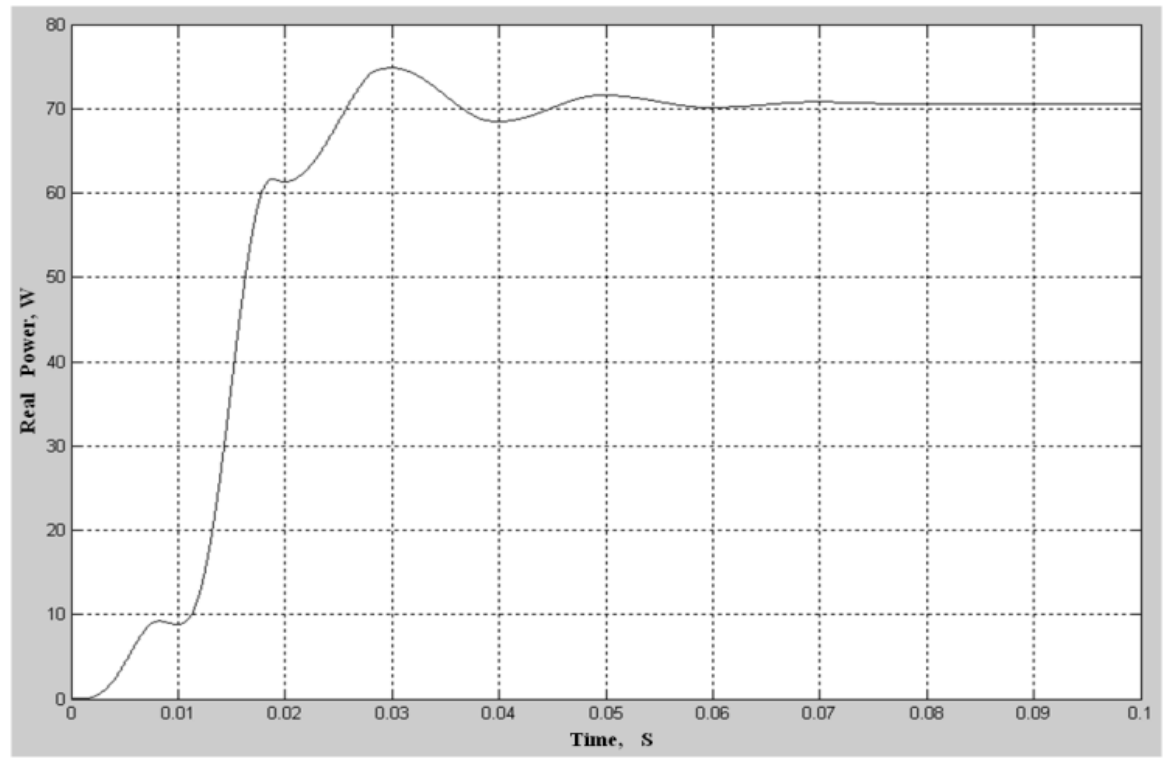

Figure 18. Output Real Power at $\sigma=45^{\circ}$

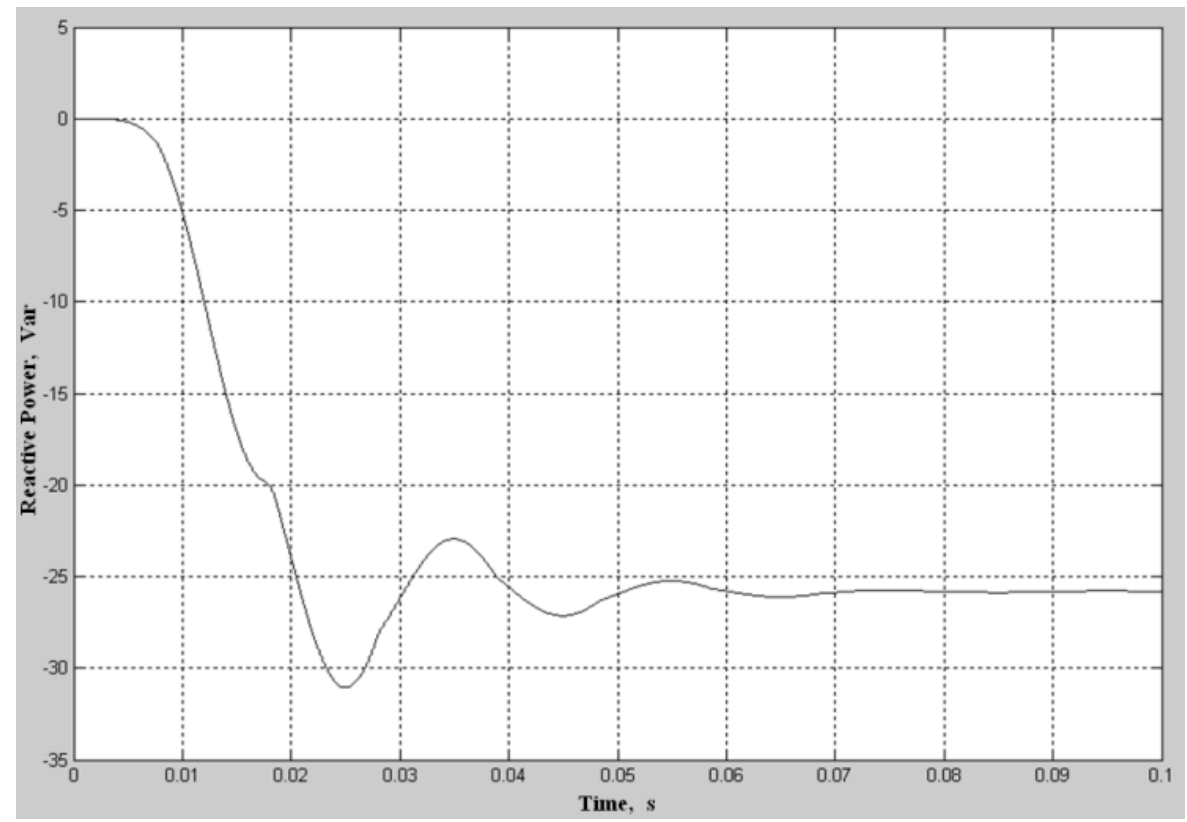

Figure 19. Output Reactive Power at $a=45^{0}$ 